\title{
Estudo de Resolução Cinética do Intermediário do Crizotinibe
}

\author{
Rebeca V. Neves, Alexandre S. França, Marcus V. M. Silva, Stefania P. de Souza, \\ Raquel A. C. Leão \& Rodrigo O. M. A. de Souza
}

O Crizotinibe é um agente anticancerígeno aprovado para tratamento de carcinoma de pulmão de células grandes. Segundo a análise retrossintética (FRANÇA e col., in press), o 1-(2,6-dicloro-3-fluorofenil) etanol é um intermediário importante, que pode ser produzido por diferentes abordagens biocatalíticas (CUI e col., 2011). Logo, o objetivo foi preparar este intermediário na sua forma enantiomericamente pura desejada. A metodologia usada foi a mesma do 1-feniletanol, descrita por Koning e col. (2011), que apresenta a estratégia de produção do álcool racêmico por redução clássica com borohidreto de sódio, seguida de acetilação via resolução cinética. Uma vez que o 1- (2,6-dicloro-3-fluorofenil) etanol contém substituintes nas posições orto, são esperados longos tempos de reação para esta transformação. Deste modo, deu-se início por rastrear a influência de doadores de acila (acetato de etila, acetato de vinila e o acetato de isopropenila) sobre o resultado da reação quando se utiliza a lipase comercial Novozyme 435 a $60{ }^{\circ} \mathrm{C}$ e ciclohexano como solvente com tempo reacional de 10 dias. Dentre os doadores de acila avaliados, o acetato de isopropenila levou aos melhores resultados, em boas conversões e alta seletividade (conv. 44\%, 99\% e.e.).

\section{Palavras Chave: Resolução Cinética; Crizotinibe.}

The Crizotinib is an anticancer agent approved for treatment of lung cancer large cells. According to the retrosynthetic analysis (France et al., in press), 1-(2,6- Dichloro-3-fluoro-phenyl)-ethanol is an important intermediary, which can be produced by different biocatalytic approaches (CUI et al., 2011). Therefore, the objective was to prepare this intermediary in its desired enantiomerically pure form. The methodology used was the same as the 1-phenylethanol, described by Koning and col. (2011), which presents a strategy for the production of the racemic alcohol by a classic reduction with sodium borohydride, followed by acetylation via kinetic resolution. Once the 1-(2,6- Dichloro-3-fluorophenyl)-ethanol contains substituents in the ortho positions, long reaction times are expected for this transformation. In this way, it was iniciated the tracing of the influence of acyl donors (ethyl acetate, vinyl acetate and isopropyl acetate) on the outcome of the reaction when using commercial lipase Novozyme 435 at $60^{\circ} \mathrm{C}$ and cyclohexane as solvent with reaction time of 10 days. Among the acyl donors evaluated, the isopropyl acetate led to the best results, in good conversions and high selectivity (conv. $44 \%, 99 \%$ e.e.).

Keywords: kinetic resolution; crizotinib. 


\section{Introdução}

O Crizotinibe (5) é um agente anticancerígeno aprovado para tratamento de carcinoma de pulmão de células grandes. Segundo a análise retrossintética (Esquema 1), ${ }^{1}$ o 1-(2,6-dicloro-3-fluorofenil)-etanol (1) é um importante intermediário, que pode ser produzido por diferentes abordagens biocatalíticas. ${ }^{2} \mathrm{O}$ interesse desse trabalho é utilizar a estratégia de Resolução Cinética para a obtenção do material enantiomericamente puro S-(2,6-dicloro-3-fluorofenil)- etanol, tendo o material racêmico como substrato, embora na estrutura química final do medicamento Crizotinibe (5) esteja presente a forma R-(2,6-dicloro-3- fluorofenil)-etanol (Esquema 1). 3 O que é explicado pelo fato de que a etapa seguinte de acoplamento do intermediário à cadeia principal é descrita na literatura pela Inversão de Mitsunobu.

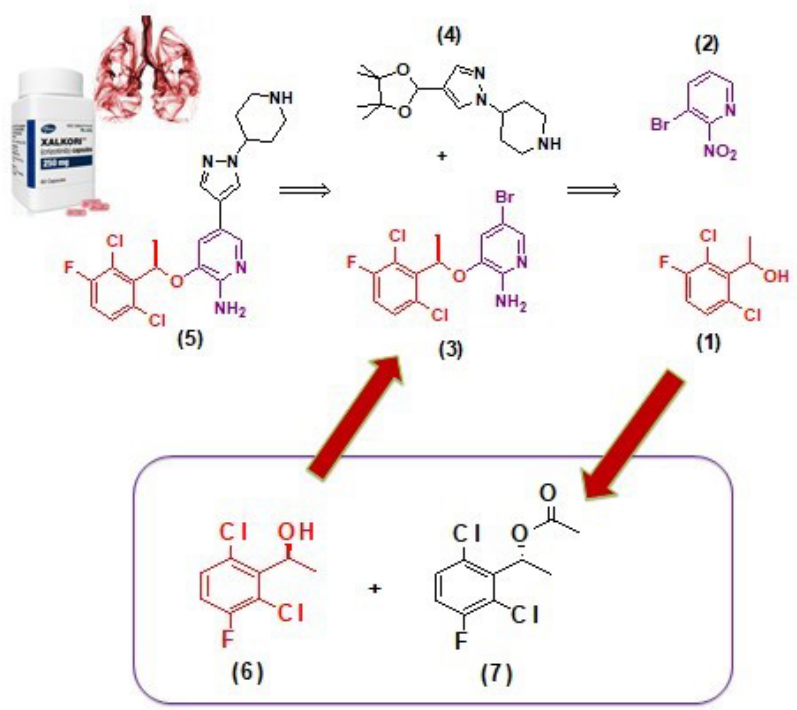

Figura 1. Análise retrossintética do Crizotinibe e produtos de resolução cinética do 1-(2,6-dicloro-3-fluorofenil)-etanol.

\section{Metodologia}

A metodologia usada foi a mesma do 1-feniletanol, descrita por Koning e col. (2011), que apresenta a estratégia de produção do álcool racêmico por redução clássica com borohidreto de sódio, seguida de acetilação via resolução cinética. Logo, inicialmente, o 1-(2,6-dicloro-3-fluorofenil)-etanol (1) foi obtido através da redução da cetona correspondente (8) com $\mathrm{NaBH} 4$ (Esquema 2). Porém, com base em resultados anteriores de resoluções cinéticas com derivados de sec-feniletanol (Souza e col., 2009), é conhecido que os álcoois arílicos orto-substituídos são menos reativos para a resolução cinética. Dessa forma, uma vez que o 1-(2,6-dicloro-3-fluorofenil)-etanol contém substituintes nas posições orto, são esperados longos tempos de reação para esta transformação. Portanto, deu-se início por rastrear a influência de doadores de acila (acetato de etila, acetato de vinila e o acetato de isopropenila) sobre o resultado da reação. Para isso, seguiu-se aplicando a estratégia de acetilação via resolução cinética a partir do álcool (1), um substrato racêmico, avaliando-se o desempenho dos diferentes doadores de acila, mediados pela lipase comercial Novozym 435 durante o período de 10 dias à $60^{\circ} \mathrm{C}$ utilizando ciclohexano como solvente (Esquema 2).

\section{Resultados e Discussão}

Como pode ser observado no Esquema 2, o acetato de isopropenila levou aos melhores resultados na resolução cinética do 1-(2,6-dicloro-3-fluorofenil)- etanol, levando ao enantiômero desejado e gerando os valores de conversão de $44 \%$ e de excesso enantiomérico de $99 \%$.

Dentre os outros doadores de acila avaliados, o acetato de vinila provavelmente não foi compatível nas condições de reação empregada, levando a uma diminuição da razão e do excesso enantiomérico (conversão de $26 \%$ e excesso enantiomérico de 95\%). Em relação ao acetato de etila, surpreendentemente, apresentou seletividade interessante (excesso enantiomérico de 99\%) com conversão moderada (conversão de 32\%). Para tentar reduzir o tempo de reação, 
uma das estratégias foi avaliar o efeito de proporções mais altas de doador de acila, mas, infelizmente, com valores superiores a dois equivalentes, a razão enantiomérica decresceu (de um valor E>200 para $\mathrm{E}=31$ ), evidenciando que a esterificação química prevaleceu. Outra tentativa foi testar outras lipases, mas não foram encontrados melhores resultados quando comparados à Novozyme 435.

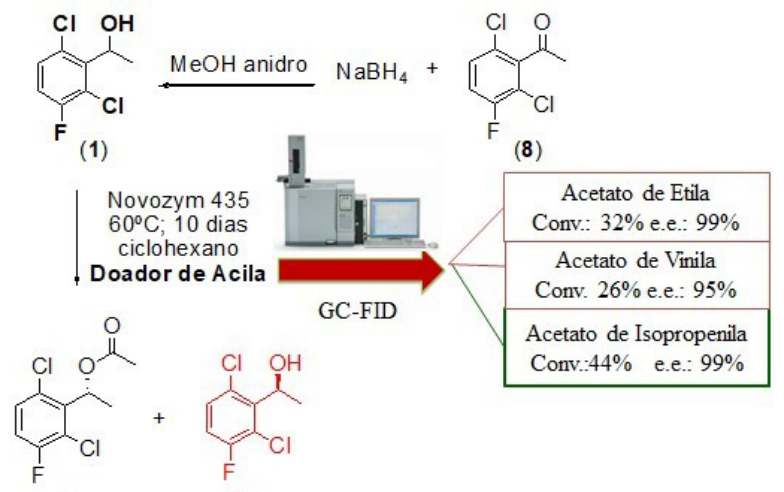

(7)

(6)
3. Cui, J. J. et al.; Journal of Medicinal Chemistry. 2011, 54, 63426363.

4. Silva, M. V. M. et al.; RSC Adv., 2015, 5, 102409-102415.

\section{Rebeca V. Neves', Alexandre S. França', Marcus V. M. Silva', Stefania P. de Souza', Raquel A. C. Leão ${ }^{2}$ \& Rodrigo O. M. A. de Souza ${ }^{2 *}$}

\footnotetext{
1-Faculdade de Farmácia, Universidade Federal do Rio de Janeiro.

${ }^{2-}$ Universidade Federal do Rio de Janeiro, RJ-Brasil

*E-mail: souzarod21@gmail.com
}

Figura 2. Redução da cetona (8) e resolução cinética enzimática do álcool (1).

\section{Conclusões}

Foram desenvolvidas diferentes abordagens para a produção de S-(2,6-dicloro-3-fluorofenil)-etanol (6), um importante intermediário do Crizotinibe, de forma a avaliar 3 diferentes doadores de grupo acila. A resolução cinética foi realizada com boa conversão (44\%) e alta seletividade (99\%), permitindo deste modo a aplicação de novos estudos em relação aos outros parâmetros reacionais e a avaliação de estratégias como a resolução dinâmica.

\section{Referências Bibliográficas}

1. Koning, P. D. et al.; Organic Process Research \& Development 2011, 15, 1018.-1026

2. França, A. S. et al.; Bioorganic \& Medicinal Chemistry . 2017, (in press). 